\title{
LA CRISIS CATALANA DE LA BAJA EDAD MEDIA: ESTADO DE LA CUESTIÓN
}

por

\section{GaSPAR FeLIU}

Universitat de Barcelona

RESUMEN: La tesis de Pierre Vilar sobre la decadencia de Cataluña en la Baja Edad Media tiene cuarenta años. Este trabajo intenta revisar las diferentes intepretaciones que se ban publicado desde entonces y plantear una revisión de la tesis, en diversos sentidos: distinguir entre los factores de decadencia y los de atraso, calibrar la importancia de cada uno de los factores y momentos de crisis y su incidencia sobre el conjunto de la economía y poner también de relieve los momentos de crecimiento y sus factores. El resultado es una visión más compleja y menos monolítica de la decandecia y el atraso de Cataluña a finales de la edad media.

Palabras Clave: Catalunya. Baja Edad Media. Crisis.

ABSTRACT: Pierre Vilar's thesis about the decline of Catalonia during the Late Middle Ages was formulated forty years ago. This paper reviews the different interpretations published afterwards and, at the same time, suggests several adjustments to the original thesis. These adjustments include the distinction between factors causing decline and delay, assessing the relative importance of each and their effect on the economic system, and also the clear-cut identification of periods of growth. The result is a more complex and less monolithic vision of the decline and delay of Catalonia at the end of the Middle Ages.

KEY WORDS: Catalonia. Late Middle Ages. Crisis.

En el último número de los Estudios de Historia Moderna, que se abría con la notica de la muerte de Jaume Vicens Vives ${ }^{1}$, Pierre Vilar publicaba la primera

1 La revista llevaba como año de publicación 1956-1959, pero la noticia de la muerte de Vicens estaba fechada en septiembre de 1960. 
versión de lo que sería el capítulo correspondiente a la Baja Edad Media en su Catalogne ${ }^{2}$, trabajo que es sin duda más conocido por su traducción al castellano en las múltiples ediciones de Crecimiento y desarrollo ${ }^{3}$. Desde entonces se ha llevado a cabo una enorme cantidad de investigación histórica, se ha profundizado en aspectos poco atendidos por Vilar, han sido discutidos algunos puntos concretos de su planteamiento, se han editado incluso diversas obras de síntesis, pero no se ha planteado una hipótesis global alternativa.

Mi propósito es recordar la tesis de Vilar y las principales participaciones posteriores en el debate para plantear a continuación una revisión de las principales propuestas y acabar con una hipótesis explicativa que tenga en cuenta los aspectos políticos de la crisis, pero sobre todo los económicos, puesto que unos y otros, aunque interrelacionados, tienen factores, ritmos y profundidades diferentes ${ }^{4}$.

\section{LA TESIS DE VILAR}

Recordemos los puntos básicos de la tesis de Vilar, para lo cual casi basta con listar los epígrafes de su trabajo: el período de plenitud catalan corresponde a los años 1250 a $1350^{5}$, o sea desde las conquistas de Mallorca y Valencia hasta la Peste Negra. Durante este siglo, en rigor desde comienzos del siglo XIII, la disponibilidad de hombres y de capitales hizo posible la conquista y el poblamiento de los nuevos territorios, la intervención diplomática, militar y comercial en el norte de África, la recuperación de los derechos hereditarios en

\footnotetext{
2 VILAR, Pierre: La Catalogne dans l'Espagne Moderne. Recherches sur les fondements économiques des structures nationales. París, 1962, 3 vol.: 717, 586 y 570 pp. respectivamente. Traducción catalana: Catalunya dins l'Espanya moderna. Barcelona, 1964-1968. Traducción castellana reducida: Cataluña en la España moderna, Barcelona,1978. Cito por la traducción catalana.

3 VILAR, Pierre: «Le déclin catalan du Bas Moyen-Âge. Hypothèses sur sa chronologie», en Estudios de Historia Moderna (Barcelona) 6 (1956-1959) p. 1-68. Traducción castellana: «El declive catalán de la baja Edad Media. (Hipótesis sobre su cronología).» En VILAR, Pierre: Crecimiento y desarrollo. Economía e bistoria. Reflexiones sobre el caso español. Barcelona, $2^{\mathrm{a}}$ ed.,1974, p. 252-331. Cito por esta última edición.

${ }^{4}$ En el origen de este trabajo está una invitación de Enrique Llopis para impartir una sesión sobre el tema en el seminario de Historia Económica del Departamento de Historia Económica II de la Universidad Complutense de Madrid. El resultado final debe mucho a los comentarios del relator José Antonio Sebastián, del mismo Enrique Llopis y de Juan Hernández Andreu en aquella sesión, y a los de Carles Sudriá, Ricard Soto i Enric Tello en una nueva presentación en el seminario del Departamento de Historia e Instituciones Económicas de la Universitat de Barcelona; quiero dejar constancia de mi agradecimiento a todos ellos, así como a Antoni Riera i Antoni Furió, que realizaron sendas lecturas críticas del trabajo. Por supuesto, los defectos y errores que puedan subsistir son de mi exclusiva responsabilidad.

5 Esta primera parte no aparece en el artículo citado, sino en La Catalogne, pero es sin duda el punto de partida de la propuesta de Vilar.
}

Hispania, LXIV/2, núm. 217 (2004) 435-466 
Sicilia (1282), el mantenimiento a raya del Papado, Francia, Génova y Pisa, la obtención de derechos sobre Cerdeña, pero sobre todo la participación en el comercio con Oriente; sin duda por detrás de Génova y Venecia, pero de nadie más. Más adelante Vilar señala los sólidos fundamentos de la época de plenitud: capitales salidos de la tierra y de la producción artesana, espíritu de empresa, cohesión social, mano de obra abundante, sintonía con la corona: todo ello iría fallando en la etapa posterior.

A partir de 1350 , la crisis general europea se abate con fuerza sobre Cataluña. La diferencia no radica en esta afectación general, sino en las dificultades para seguir el ritmo europeo en la superación de la crisis: Cataluña saldrá de la depresión tarde y debilitada, para no volver a ocupar ni de lejos su situación anterior en la jerarquía de países europeos. A la hora de explicar la crisis, Vilar titula en primer lugar «los hombres y la tierra» para subtitular inmediatamente «dos siglos de catástrofes demográficas» y «del despoblamiento del campo a la crisi social agraria». La secuencia es clara: la peste negra y sus secuelas producen la desaparición de muchas explotaciones, el abandono de muchas tierras, en enfrentamiento entre un campesinado con mejor pasar y unos señores con rentas insuficientes, pugna que a través de la reacción señorial provocará el secular conflicto remença. La disminución de la producción agraria y del mercado campesino paran el primer motor del crecimiento catalán. El motor urbano parece continuar durante cierto tiempo: todavía en 1359 Pedro el Ceremonioso inicia la ampliación de la muralla de Barcelona, pero el nuevo recinto no se llenará hasta el siglo XVIII. Para Vilar este hecho señala el paso de una coyuntura de desarrollo a una coyuntura involucionista. Pero a continuación indica que el apogeo del gran comercio se prolonga hasta mediados del siglo XV, sin que ello sea contradictorio: el gran comercio, el desarrollo bancario e incluso la producción para la exportación, no están ligados de inmediato a la situación demográfica y agraria; incluso en un primer momento la acumulación de fortunas y la abundancia de moneda (la misma moneda debía satisfacer las necesidades de una población disminuida), provoca un alza de precios, un momento de euforia. De hecho la mayor parte de los grandes edificios góticos proceden de este período: el salón del Tinell (palacio real), la lonja, Santa Maria del Mar, rápidamente reconstruida, las casas palacios de mercaderes en la calle Montcada, etc. Sin embargo el comercio catalán toca techo en algún momento de la primera mitad del siglo XV.

A pesar de esta prosperidad aparente, Vilar coloca entre 1380 y 1420 los primeros signos de desequilibrio y debilidad: asalto a los barrios judíos, dificultades en Cerdeña, enfrentamientos con Génova, pérdida de peso de Cataluña dentro de la corona de Aragón. De hecho la coyuntura catalana sigue de cerca la europea, pero presenta algunos puntos de dificultad, como la disminución de la ley del florín, moneda de prestigio, que en 20 años pierde una cuarta parte de su contenido en oro, y los problemas de equilibrio entre las monedas de oro y de plata, entre las monedas nacionales y extranjeras. Más importante es el peso creciente de

Hispania, LXIV/2, núm. 217 (2004) 435-466 
la deuda sobre una economía en crisis y lo que Vilar denomina, con interrogante, el paso de una sociedad emprendedora a una sociedad rentista.

La crisis aparece con toda crudeza a mediados del siglo XV. Los datos del impuesto del periatge, que grava el tráfico portuario son claros: el valor del comercio se habría reducido a una cuarta parte en poco más de diez años ${ }^{6}$. Vilar se limita a constatar el hecho y a una referencia a la larga hostilidad con Génova, para describir a continuación sus consecuencias: el divorcio entre el imperialismo de Alfonso el Magnánimo y la realidad y los deseos de la sociedad mercantil barcelonesa; y los enfrentamientos urbanos (la busca i la biga) para dilucidar qué grupo social debe cargar con el peso de la crisis, si los rentistas o los productores. Los puntos de fricción son la moneda y el dilema proteccionismo-librecambio; el campo de batalla los cargos municipales. La crisis comercial y urbana coincide además con la organización de los payeses de remença para llevar ante el tribunal real su petición de abolición de la servidumbre y los «malos usos».

Todo ello, más el conflicto político y sentimental en torno al príncipe de Viana, llevará a la guerra civil. En este punto, Vilar no puede ser más lacónico ni más preciso: la guerra sale de la crisis, la guerra lleva la crisis a su punto máximo, la crisis sobrevive a la guerra e incluso a los primeros intentos de reorganización. Sólo después de la pacificación del campo con la Sentencia Arbitral de Guadalupe (1486) y de nuevas medidas proteccionistas y monetarias, Cataluña saldrá de la crisis para instalarse en la mediocridad.

\section{LAS REVISIONES DE LA CRISIS}

La hipótesis de Vilar fue rápidamente aceptada por Vicens Vives. ${ }^{7}$ Lo que propongo ahora es examinar los principales trabajos que se han ocupado directa o indirectamente del tema para ver si, y en que grado, aceptan las ideas de Vilar o las modifican.

6 VILAR («el declive...», p. 209), no puede menos que notar que las cifras son poco seguras, en especial las altísimas de 1433-34.

7 VICENS I VIVES, J.: Els Trastàmares (segle XV), Barcelona, 1956, p. 17-26; VICENS I VIVES, Jaime; SuÁrez Fernández, Luis; CARrère, Claude: «La economía de los países de la Corona de Aragón en la Baja Edad Media", en VI Congreso de Historia de la Corona de Aragón. (Cagliari-Alguer 1957). Madrid: 1959 (republicado en: VICENS I VIVES, JAUME, Coyuntura económica y reformismo burgués, Barcelona, 1969). Los pies de imprenta resultan engañosos, sobre todo por el retraso que sufrió la publicación del último número de los Estudios de Historia Moderna tras el fallecimiento de Vicens Vives. En realidad, poco antes Vicens había elaborado su propia visión de la crisis, de la que sin duda Vilar es en parte deudor (VICENS VIVES, Jaime: «Evolución de la economía catalana durante la primera mitad del siglo XV", a IV Congreso de Historia de la Corona de Aragón. Actas y Comunicaciones. Vol. I. Ponencias. Palma de Mallorca, 1955, p. 185-207); pero Vicens no retraía la crisis más allá de 1380 y sólo se refiere a la obra de Vilar como un "prólogo inédito de una importantísima obra sobre el siglo XviII catalán».

Hispania, LXIV/2, núm. 217 (2004) 435-466 
La primera revisión de la crisis posterior a los trabajos de Vilar y de Vicens se encuentra en el prólogo que escribió Ramon d'Abadal para el volumen XIV de la Historia de España Menéndez Pidal ${ }^{8}$, en el que sigue de cerca el esquema de Vilar. Los puntos sobre los que d'Abadal pone especial énfasis son el doble efecto de la peste sobre la disminución de la población en el campo, a través de la mortaldad directa y de la emigración para llenar el vacío de población en las ciudades; el aumento de rentas que la epidemia facilitó a los sobrevivientes, que permitió una etapa de aumento de precios y salarios, de euforia económica; y la afirmación de que los señores feudales solamente podían compensar la caída de sus rentas mediante la guerra. La guerra con Castilla, que duró con interrupciones de 1356 a 1375 , permitió sobrevivir a la clase militar a costa del aumento de los impuestos y del endeudamiento del rey y de los municipios.

Con una óptica más centrada en Barcelona y en el comercio, Claude Carrère presenta la Barcelona de 1380 a 1420 como un gran centro comercial internacional, cuya prosperidad depende más de la cotización de las especias en Alejandría o Brujas que de la cosecha en el Ampurdán o el Urgel ${ }^{9}$. Su visión, sesgada por las razones indicadas, tiene la ventaja de insertar la crisis barcelonesa en el contexto internacional de dificultades, lo que permite observar mejor determinados aspectos de la decadencia catalana.

En su opinión, la profundidad de la crisis barcelonesa no hay que buscarla en los problemas demográficos o monetarios, comunes al occidente europeo; tampoco en la agitación remença, que no tenía incidencia directa en la economía de la ciudad, basada en el comercio internacional, al menos hasta la guerra civil. Para fijar la cronología de la crisis, Carrère se apoya en los ingresos de la Generalitat y del municipio de Barcelona, que indican un momento de dificultades en la década de 1420; pero señala que a partir de 1410 resulta difícil encontrar arrendatarios de los derechos. Carrère cree en el fondo de la cuestión se halla la pérdida de competitividad de la pañería catalana en los mercados internacionales ${ }^{10}$ : los partidarios de devaluar la moneda intentaban recuperar la competitividad a través de la baja de precios. Las dificultades de la industria textil provocarían una caída de los salarios, que cifra entre un 15 y un $20 \%, 11$ a la que habría que añadir una menor oferta de trabajo. En su opinión, muestra

8 ABADAL, Ramon d': «Pedro el Ceremonioso y los comienzos de la decadencia política de Cataluña», en SuÁRez Fernández, Luis; Reglà CAMPISTOL, Juan: La crisis de la reconquista (c. 1350-c.1410), Madrid, 1966: Historia de España, fundada por R. Menéndez Pidal, vol. 14, pp. VIICIII. Traducción catalana como obra independiente: ABADAL, Ramon d': Pere el Cerimoniós $i$ els inicis de la decadència política de Catalunya, Barcelona, 1974, 301 pp.

9 CARrÈre, Claude: Barcelone centre économique à l'époque des difficultés. 1380-1462. París-La Haya, 1967, 2 vol., 993 pp. Traducción catalana: Barcelona 1380-1462. Un centre econòmic en època de crisi. Barcelona, 1977. Cito por la traducción, p. 7.

10 CARrère, Barcelona..., p. 153.

11 Por desgracia el único argumento para apoyar el aserto es la caída del precio de los paños (CARRÈRE, Barcelona..., p. 151). 
y resultado de este malestar sería el asalto a la judería en $1391 .^{12}$ En todo caso la caída del consumo parece evidente entre 1410 y 1430 , seguida a partir de 1430 de un claro descenso de los derechos de entrada, es decir de las importaciones; la suma de ambos hechos no podía tener otra resultado que una clara contracción económica.

Carrère ${ }^{13}$ sigue a Vilar al considerar como primera señal de la crisis la serie de bancarrotas iniciadas en 1381 y señala que la quiebra de la banca Gualbes en 1406 representa el punto final de la liquidación de la banca trecentista catalana. A mi entender, sin embargo, las quiebras, más que entre las consecuencias de la crisis, deben computarse entre sus causas ${ }^{14}$ : la pérdida de capitales y la desconfianza ante la banca produjo una rápida restricción de las finanzas catalanas. El problema se agravó con la crisis y los enfrentamientos en torno a la moneda; aparte de la especulación que acompaña a los sistemas bimetálicos en momentos de rápida variación de la ratio, el sistema monetario catalán sufrió mucho a causa de la invasión de mala moneda francesa ${ }^{15}$ y sobre todo por la pugna entre la moneda fuerte, defendida por las instituciones y la $\operatorname{biga}^{16}$, y la devaluación que deseaban productores y exportadores (la busca $)^{17}$.

Carrère es rotunda en cuanto al desencadenamiento de la crisis: 14251450, como figura en el título del capítulo 9 de su obra. En este momento, Carrère pone en primer término la caída de la población: la repercusión del

\footnotetext{
12 Hay que tener en cuenta sin embargo que se trata de un progrom generalizado, con claras raíces andaluzas, y que además tampoco se cita la participación de artesanos entre los principales grupos asaltantes

13 CARrère, Barcelona..., p. 164.

${ }_{14}$ El hundimiento de la banca de Pere des Caus y Andreu d'Olivella se debió a la incapacidad de la Corona para hacer frente a la deuda acumulada, a intereses altísimos. No se trataba tanto de la insolvencia de la monarquía como del coste que representaba para ésta hacer frente a sus deudas, para lo cual habría sido necesario vender partes importantes del patrimonio real. Ni Pedro el Ceremonioso deseaba debilitar más su posición ni le faltaron consejeros aúlicos que le convencieron de utópicas soluciones para solventar su endeudamiento; no hay que dejar de lado sin embargo el rencor del rey contra Pere des Caus, a quien acusaba de no haberle concedido un crédito prometido (FeliU, Gaspar: «El maestro racional de la Corona de Aragón y la revisión de cuentas de la Taula de Canvi de Pere des Caus y Andreu d'Olivella». IX Congreso de la Asociación Española de Contabilidad y Administración de Empresas. Salamanca, 1997, pp. 935-955); por otra parte, la afirmación de Carrère en el sentido que la quiebra afectó a mercaderes y pañeros no resulta avalada por las listas de acreedores de la banca des Caus y d'Olivella (Arxiu Històric de Protocols de Barcelona, not. Francesc Ladernosa, manual 35).

15 Queda por explicar sin embargo porqué las monedas francesas seguían siendo aceptadas en Cataluña a la par, como si no hubiesen sufrido merma en su contenido metálico.

${ }^{16}$ La biga era el partido de los rentistas y los comerciantes importadores, o sea del patriciado urbano.

${ }_{17}$ La devaluación del dinero implicaba a la vez la de la moneda de cuenta, basada en él. La devaluación se obtenía aumentando la cotización del croat, la moneda grande de plata. Con ello, todas las cantidades fijadas en moneda de cuenta — salarios, rentas- representaban una menor cantidad de plata por el mismo nominal.
}

Hispania, LXIV/2, núm. 217 (2004) 435-466 
descenso demográfico habría tardado casi un siglo en afectar a Barcelona, pero a partir de 1425 la ciudad pierde población ${ }^{18}$ y se nota falta de mano de obra. Los efectos de esta última carencia se intentan paliar mediante la limitación de los salarios e importación de esclavos. A pesar de ello, menudean las quejas por el descenso de la producción, tanto en la industria textil como en la naval, la tenería o en el coral; los resultados observables son las luchas entre gremios, la cerrazón de los mismos y el aumento de las desigualdades en su interior: los maestros ricos empiezan a fiar materia prima a los menos afortunados, «primer paso en el engranaje de la sujección económica» ${ }^{19}$. También el comercio decae; Carrère hace notar la substitución de la galera por la carabela o el ballenero, naves mucho más pequeñas, que representan la adaptación a un tráfico disminuido. Otra demostración: de principios de siglo hasta 1423 partían cada año para oriente unas trece o catorce embarcaciones; a partir de 1425 , lo normal son siete u ocho. Todavía más demostrativa es la cantidad de quiebras entre los mercaderes y artesanos. A todo ello vienen a añadirse los gastos y por tanto las exigencias de la monarquía, considerados excesivos, sobre todo los causados por la impopular conquista de Nápoles; y, como censecuencia de todo ello, la lucha política y económica por el dominio del municipio barcelonés, con la intervención real en favor de la busca como única forma para romper el monopolio que la biga ejercía a través de la cooptación para los cargos. Esta intromisión del monarca en el régimen municipal barcelonés fue responsable en gran parte del estallido de una agotadora guerra civil (1462-1472) de la que Barcelona saldría reducida al rango de capital provincial.

A pesar de algunos puntos de disconformidad y de diferencias de enfoque, Carrère se mantiene básicamente dentro de la hipótesis de Vilar. La principal alternativa a ésta la representa la obra de Mario del Treppo ${ }^{20}$. Aunque dedica pocas páginas a tratar de «las fases de la decadencia catalana» y afirma que sólo intenta proponer algunas correcciones o precisiones a la cronología de la crisis fijada por Vicens y Vilar, en realidad propone una visión alternativa, expresada tajantemente: la brutal destrucción de la prosperidad económica fue obra de la guerra civil. Aunque hacia 1450 existían difusas señales de malestar, entre 1454 y 1462 la economía catalana muestra una clara fase de crecimiento.

En apoyo de este aserto, del Treppo defiende una larga fase de prosperidad durante el primer tercio del siglo, con un máximo hacia 1420-1433. La etapa siguiente (1433-1454) es el punto en que la argumentación de del Treppo es

\footnotetext{
18 Guàrdia y García Espuche creen que a lo largo de los siglos XIV y XV la población barcelonesa creció o se estabilizó; GARCíA ESPUCHE, Albert: «Consolidación de una estructura urbana: 13001516», en SOBREQUÈS, Jaume (dir.): Història de Barcelona. 3. La ciutat consolidada (segles XIV $i$ XIV), Barcelona, 1992, p. 38.

19 CARRÈre, Barcelona..., p. 217.

${ }^{20}$ TREPPO, Mario del: I mercanti catalani e l'espansione della Corona d'A ragona nel secolo XV. Nápoles, 1972. Traducción catalana: Els mercaders catalans $i$ l'expansió de la Corona catalano-aragonesa. Barcelona, 1976. Cito por la traducción.
} 
más novedosa, aunque también más discutible. La raíz de la cuestión es la valoración de la actuación de Alfonso el Magnánimo: su imperialismo político y económico, doblado de medidas dirigistas y proteccionistas, ¿frenó la crisis o la profundizó? ¿los costos de su política fueron mayores o menores que sus beneficios? Del Treppo valora positivamente la obra del monarca, pero no deja de observar que la prosperidad de una ciudad como Barcelona se basaba en el gran comercio internacional y en actividades de tipo especulativo, vinculadas en gran al capital extranjero, la marina y la industria textil; el crecimiento de una economía de este tipo exige el mantenimiento de las relaciones internacionales, el flujo de crédito y una cierta seguridad y libertad de contratación, condiciones que en parte se habrían visto comprometidas por el imperialismo alfonsino y por la preferencia del monarca de una política económica alternativa, basada en la industrialización, la potenciación de la marina y el proteccionismo. Con ello sometió la economía de sus estados, y en especial el comercio catalán, a momentos de dificultades, aunque del Treppo considera que éstas quedaron compensadas con creces por el posterior dominio sobre Nápoles.

Del Treppo tampoco es tan pesimista como Vilar al juzgar la época posterior a la guerra. Acepta la pérdida de la marina y del gran comercio, pero recuerda que la industria, con el apoyo de una política proteccionista en el interior y la obtención de privilegios en Nápoles, Sicilia y Cerdeña, pudo recuperar los mercados tradicionales, incluso temporalmente el de Levante. En vez de la afirmación de Vilar de que la guerra acentuó las deficiencias de un sistema que ya estaba en crisis, del Treppo cree que sería más exacto decir que, antes del conflicto, el sistema, que había sufrido una crisis coyuntural, se encaminaba lentamente a su renovación, que la guerra hizo imposible.

Resumiendo: para del Treppo hasta la guerra civil no habría depresión, sino crecimiento global, aunque quizá desacelerado a partir de $1433^{21}$. En la parte central del siglo XV se irían produciendo cambios en la estructura y en la política económicas, con una mayor atención a la producción destinada a la exportación que al tradicional comercio de reexportación, cambios que provocarían graves enfrentamientos sociales y que constituirían una de las raíces de la guerra. En su opinión, la importancia de la guerra civil en la decandencia de Cataluña fue de tal magnitud que, a su lado, el resto de causas que pueden invocarse carecen en realidad de importancia.

Dufourcq tercia en el tema de la crisis económica catalana en su síntesis sobre la economía de la España cristiana ${ }^{22}$. Aunque en conjunto acepta el esque-

${ }^{21}$ Hay que tener en cuenta, sin embargo, que del Treppo observa sólo la realidad del siglo XV y sólo desde el punto de vista del comercio internacional con lo cual «el primer motor de la crisis» de Vilar (los aspectos demográficos y agrarios) queda fuera de su campo de observación.

${ }^{22}$ En DufourcQ, CH.-E.; Gautier-DalChÉ, J.: Histoire économique de l'Espagne chrétienne au Moyen Age, París, 1976, 288 pp. Traducción castellana con el título Historia Económica y Social de la España cristiana en la Edad Media, Barcelona, 1983, 456 pp. Las citas son de la edición castellana.

Hispania, LXIV/2, núm. 217 (2004) 435-466 
ma de Vilar y, como éste, empieza tachando de catastrófico el siglo XIV, añade que es necesario relativizar el encadenamiento de dificultades y recomienda prudencia a la hora de valorar el impacto del descenso de población. También critica la utilización que suele hacerse de los precios como indicador de la marcha de la economía. En cambio, pone el émfasis en el aumento de la fiscalidad y las quiebras bancarias; sin negar que en su raíz pudiera hallarse la inversión de la coyuntura demográfica y económica, indica que la causa directa fue la insolvencia de la monarquía. Pone también de relieve la importancia y el trasfondo político de la pérdida de posiciones en Sevilla, causada por la guerra entre los dos Pedros y a la rivalidad con los genoveses, preponderantes en la corte castellana, justo en el momento en que Sevilla estaba a punto de convertirse en uno de los grandes centros comerciales internacionales. En definitiva, señala que la crisis no se puede reducir a causas socioeconómicas, ni mucho menos a la secuencia crisis demográfica - crisis económica.

Más aún, al lado de los problemas del siglo XIV catalán, destaca sus logros: un importante empuje de la producción pañera, la mejora de los instrumentos comerciales, el buen comportamiento de la moneda (al menos en términos comparativos), la abundacia de capitales y el auge de la construcción naval. Aunque advierte algunas dificultades a partir de la muerte del Ceremonioso, no cree que se pueda hablar de crisis antes de 1430; alrededor de este año, el comercio internacional llega a su punto máximo, se produce el decaimiento de la industria pañera y de la construcción naval, resulta difícil e impopular sufragar la conquista de Nápoles y se produce el enfrentamiento entre la biga y la busca: la intervención del rey a favor de ésta última con el golpe de estado municipal de 1453 (designación directa de los miembros del Consell de Cent) marcó claramente la división de campos que llevaría a la guerra civil (1462-1472), que no duda en tildar de «catástrofe».

Interviene también en la polémica Ruiz Doménec ${ }^{23}$, quien empieza con ataques poco comunes a Vicens i Vilar: «la tesis de Vicens sobre la «crisis económica»... carece de todo valor para la detectación de la realidad económica de Cataluña» y «el conocimiento de la realidad de Cataluña en los siglos XIV y XV a que aspira $\mathrm{P}$. Vilar es rechazado por erróneo, en el sentido de desencaminado y confuso" ${ }^{24}$.

A su entender, los errores de la tesis Vicens - Vilar se deben principalmente a una deficiente valoración de las fluctuaciones comerciales en el Mediterráneo, «un desconocimiento casi absoluto de la agricultura» ${ }^{25}$ y a «evidentes fal-

Duforcq, que es el autor de las partes del libro relativas a la Corona de Aragón, mientras que la colaboración de Gautier-Dalché se refiere a la Corona de Castilla.

${ }^{23}$ Ruiz DoméneC, J. E.: «La crisis económica de la Corona de Aragón, crealidad o ficción historiográfica?, en Cuadernos de Historia anexos a la revista Hispania (Madrid) 8 (1977), pp. 71-117.

${ }^{24}$ RUIZ DOMÉNEC: «La crisis...», p. 74.

25 «confundida por $\mathrm{J}$. Vicens y seguidores con la economía rural, y por P. Vilar con los problemas demográficos». RUIZ DOMÉNEC: «La crisis...», p. 88.

Hispania, LXIV/2, núm. 217 (2004) 435-466 
tas de lógica, de sistematización y de teoría». La razón de todo ello es que lo que Vicens y Vilar «no ignoraban... era infinitamente inferior a lo que ignoraban» ${ }^{26}$; para afirmar a continuación que P. Vilar debió acudir a la «ley de la tendencia decreciente de la cuota de ganancia», de Marx, "pero creo que P. Vilar desconoce esta formulación teórica marxista o, al menos, la evita terriblemente», para apostillar "Me produce estupor comprobar que muchos autores... siguen considerando a $\mathrm{P}$. Vilar un historiador marxista» y rematar «este esquema de decadencia propuesto por $\mathrm{P}$. Vilar me parece, a nivel descriptivo, mediocre; a nivel analítico, inoperante» ${ }^{27}$.

Las críticas concretas de Ruiz Doménec a la tesis de Vilar se refieren a la crisis del gran comercio, la crisis demográfica, el hundimiento de la producción y la parálisis técnica de los negocios. Por lo que respecta a la crisis del gran comercio, Ruiz Doménec acepta la tesis de del Treppo. Sobre la crisis demográfica, su conclusión es «que no sabemos nada» 28 , para lo cual niega tanto la sobrepoblación relativa de la Europa anterior a la peste como cualquier capacidad explicativa a los fogajes. Al tratar del hundimiento de la producción se refiere a la disminución de la producción cerealícola, que, en su opinión, podría explicarse no tanto por una crisis agrícola como por un cambio en las condiciones del mercado, que hacían preferible la importación de cereales a su producción en Cataluña ${ }^{29}$, para pasar a continuación a discutir si la conquista de Nápoles por parte de Alfonso el Magnánimo fue o no favorable para la economía catalana. Finalmente, en el apartado sobre la "parálisis técnica en los negocios», para negar que se produjese una esterilización de capitales en la deuda pública y el «divorcio» de la clase mercantil respecto a la empresa napolitana, Ruiz Doménec acude a la pregunta retórica de Marx sobre si la cuota de ganancia más elevada que obtiene el capital invertido en el comercio exterior contribuye a la elevación de la cuota general de ganancia ${ }^{30}$. La conclusión de todo ello es: «Quiero afirmar tan sólo - y para terminar- que la tautología en la que cae la tesis Vicens - Vilar es el riesgo propio de un pensar que no se unifica en su estructura con la dialéctica» ${ }^{31}$.

Batlle hace una buena síntesis de las posiciones de Vilar y del Treppo ${ }^{32}$ para concluir que se trata de una polémica inconclusa, en la que sólo queda clara la brutal caída provocada por la guerra civil y los intentos de recuperación en

26 RuIz DOMÉNEC: «La crisis...», p. 89.

27 RUIZ DOMÉNEC: «La crisis...», p. 91-92.

28 RUIZ DOMÉNEC: «La crisis...», p. 99.

29 RUIZ DOMÉNEC: «La crisis...», p. 103-105.

30 RUIZ DOMÉNEC: «La crisis...», p. 109.

${ }^{31}$ RUIZ DOMÉNEC: «La crisis...», p. 115.

32 BATLLE, Carme: L'expansió Baixmedieval, segles XIII-XV. Vol. III de VILAR, Pierre (dir): Història de Catalunya. Barcelona, 1988, p. 249-321. A pesar del título, Batlle apenas hace mención de la crisis en su obra anterior (BATLLE, Carme: La crisis social y económica de Barcelona a mediados del siglo XV. Barcelona, 1973).

Hispania, LXIV/2, núm. 217 (2004) 435-466 
tiempos de Fernando el Católico así como que la polémica no puede ser dilucidada sin avances en la investigación, puesto que cada autor maneja datos en gran parte diferentes. El único punto en que Batlle pone de manifiesto su opinión es en la consideración de los años centrales del siglo XV como críticos, ya que se produce a la vez una recesión de la producción textil, un bache comercial y graves agitaciones urbanas y rurales, marcadas por el malestar de señores y patricios ante el favor de la monarquía a la busca y los remences. Señala también que la recuperación posterior a la guerra se vio dificultada por la fuerte pérdida de naves a lo largo del conflicto, de manera que las mercaderes barceloneses se veían obligados a cargar en naves extranjeras.

Salrach tiene dos descripciones de la crisis (1981 y 2002)33; me referiré a la segunda, que es más reciente y completa. Tras advertir que se trata de «un tema problemático, objeto de un debate que permanece abierto» ${ }^{34}$, indica su punto de vista favorable a la idea de una crisis global, a partir del esquema de Vilar, reforzado con las aportaciones de la crisis sistémica de Bois ${ }^{35}$.

El punto de partida es por tanto el fin de la expansión medieval, con la población creciendo más que la puesta en cultivo de nuevas tierras y la dedicación parcial a cultivos no alimentarios, lo que hacía más frecuentes los déficits trigueros. La malnutrición profundizó el impacto de la Peste Negra, pero no resolvió el problema del desequilibrio entre población y producción porque forzó la reacción de los señores, que intentaban contrarrestar el hundimiento de sus rentas, de manera que Cataluña continuó perdiendo población hasta el mínimo del fogaje de 1497.

Advierte sin embargo de un momento de recuperación entre 1420-1430 y mediados de siglo, pero la bonanza fue corta y poco provechosa, ante la pérdida del mercado de las especias en el sur de Francia y la disminución de las exportaciones de tejidos a Sicilia. La depresión vuelve a manifestarse claramente entre 1445 y 1455 , años de devaluaciones monetarias, división de la clases dirigentes y luchas para imponer soluciones diversas a la crisis, preludio todo ello de la guerra civil.

La dureza de la depresión en Cataluña se debe en parte a la extroversión de su economía: la conversión parcial a una agricultura especulativa y la importancia del sector manufacturero, factores favorables en época de crecimiento, conferían una gran fragilidad a su economía en época de crisis «lo que explica

33 Salrach, Josep M.: «Dels orígens a 1714», en Balcells, Albert (coord.), Història dels països catalans, Barcelona, 1981, pp. 890-1015.Y SALRACH, Josep M.: «La Corona de Aragón» en CARRASCO, Juan; SALrach, Josep $M^{\mathrm{a}}$; VAldeÓn, Julio; Viguera, $\mathbf{M}^{\mathrm{a}}$ Jesús: Historia de las Españas medievales, Barcelona, 2002, pp. 306-342.

${ }^{34}$ SALRACH, Historia de las Españas... p. 310.

35 BoIs, Guy, La grande dépression médievale, XIV'-XV'siècles. Le précédent d'une crise systèmique. $\mathrm{Pa}-$ rís, 1999. Traducida con el título: La gran depresión medieval: siglos XIV-XV: el precedente de una crisis sistémica. Valencia, 2001, 237 pp. 
el hundimiento de Cataluña como potencia, al mismo tiempo que Aragón y Valencia afrontaban mejor la crisis» ${ }^{36}$.

El primer motor de la crisis catalana ha de buscarse pues en el campo, de la misma forma que el crecimiento se había iniciado en él. Por tanto «el equilibrio de la prosperidad debió romperse durante la primera mitad del siglo XIV ${ }^{37}$. A partir de ahí, aparece un encadenamineto de factores negativos que podemos sintetitzar como descenso de la población, de la producción agrícola y de la renta, reacción señorial, empobrecimiento del campo, contracción del mercado (punto de engarce con la crisis urbana), competencia creciente y reacción corporativa de los gremios, adopción de medidas proteccionistas, con consecuencias negativas sobre el comercio exterior. Por su parte, la escasez de la población y de la producción impulsa un segundo grupo de factores negativos: descenso de la materia imponible, déficit, endeudamiento crónico, quiebras bancarias. Naturalmente, la crisis es terreno abonado para los especuladores, lo que explica el mantenimiento del gran negocio hasta bien entrado el siglo XV, pero Salrach no parece conceder demasiada importancia al sector mercantil: «lo importante no es tal o cual sector, sino el conjunto" ${ }^{38}$.

Tras este esquema básico, Salrach examina los diferentes aspectos de la crisis: la crisis social en el campo, representada básicamente por el conflicto remença y la diferenciación social en el seno del campesinado; ésta habría permitido a los campesinos ricos salir de la crisis de no haber intervenido la reacción señorial, pero de todos modos hizo que los campesinos ricos fuesen el grupo más beneficiado por la sentencia de Guadalupe. Crisis también urbana, clara ya con las manifestaciones de antisemitismo en 1391 y las luchas entre bandos por el dominio del poder municipal y la dirección de la política económica. Crisis fiscal, motivada básicamente por la repetición de conflictos armados en el siglo XIV (luchas internas contra las Uniones, Cerdeña, Génova, Castilla) que obligó a la corona a recurrir de forma constante a la fiscalidad extraordinaria y al endeudamiento, con el hito básico de las quiebras bancarias de 1381; conflictos que se reanudarían en el siglo XV con la conquista de Nápoles y por encima de todo con la guerra civil de 1462-1472. Crisis finalmente política, en especial con los enfrentamientos entre Alfonso el Magnánimo y las cortes, que consideraban su política excesivamente costosa dada la prostración de la economía catalana. Enfrentamientos también con el mismo Alfonso y con su hermano Juan II por la defensa de la legalidad constitucional, favorable a la oligarquía, que topaba con la tendencia al autoritarismo y los planes reformistas de los reyes Trastámaras.

En conjunto pues, la explicación de Salrach constituye una magnífica puesta al día de la tesis de Vilar: Cataluña se halla immersa en los siglos XIV y XV

\footnotetext{
36 SALRACH, Historia de las Españas... p. 314.

37 SALRACH, Historia de las Españas... p. 314

38 SALRACH, Historia de las Españas... p. 315.
} 
en una crisis general y única, que se transmite del campo a la ciudad, de la manufactura al comercio y de la economía a la política.

El estudio de Bresc no tiene como tema ni Cataluña ni la crisis, pero permite observar la coyuntura del comercio y la manufactura catalanes desde un observatorio exterior: Sicilia ${ }^{39}$. Destaca que, en la isla, los catalanes se vieron superados como transportistas por los genoveses a partir de 1340 y hasta casi un siglo después no recuperarían este papel gracias a las medidas proteccionistas de Alfonso el Magnànimo. Aunque la producción catalana dominaba el mercado de paños de calidad media, su comercialización estuvo en manos de los genoveses hasta 1390; de hecho, sólo a partir de esta fecha empezaron a asentarse en Sicilia un número significativo de comerciantes catalanes. Su dominio del mercado se prolongó hasta 1430; a continuación volvieron a predominar los genoveses, que vendían paños de Florencia, mientras empezaba la introducción de paños ingleses. Las afirmaciones de Bresc rompen, al menos para Sicilia, algunos lugares comunes como el predominio naval durante el siglo XIV y la consideración de la etapa 1380-1420 como un momento de crisis. En cambio, la pérdida del importantísimo mercado siciliano ante los genoveses a partir de 1430 es coherente con la etapa de crisis profunda del segundo cuarto del siglo XV.

Un observatorio diferente, pero no menos importante para la evolución de la coyuntura económica catalana es el comercio con Oriente, estudiado por Feliu $^{40}$. Las opiniones de los autores anteriores sobre la crisis del comercio con oriente, son dispares: Vicens Vives cree que quedó malparado durante la crisis de 1380-142041; opiniones semejantes manifiestan Madurell y García Sanz, que creen que se produjo una ruptura irreversible en $1415^{42}$, opinión parecida a la de Claude Carrère, quien fija el inicio de la crisis en 1420, aunque considera que el gran comercio se mantuvo hasta 1440 , poco más tarde que Vilar, quien ofrece la fecha de 1435 . De esta misma opinión es del Treppo, quien sitúa en 1435 el momento máximo del comercio medieval, aunque no cree que la decadencia fuese visible hasta 1450 .

En opinión de Feliu, el ritmo ascendente se rompe hacia 1415, aunque el impulso de la etapa anterior permite todavía momentos de esplendor; pero a partir de 1428 la mayor parte de los viajes no sobrepasaron Rodas. El factor básico en la pérdida de empuje comercial parecen ser los cambios que la destrucción del imperio de Tamerlán produjo en el Próximo Oriente; a ello se unió la actividad pirática de los catalanes en el Mediterráneo oriental, hecho que ha

39 BRESC, Henri: Un monde méditerranéen. Economie et société en Sicile, 1300-1450. Roma, 1986.

40 FEL.U, Gaspar: «El comercio catalán con oriente», Revista de Historia Económica (Madrid) VI, 3 (1988), pp. 689-707.

41 VICENS I VIVES, Jaume, «Evolución de la economía catalana durante la primera mitad del siglo XV», En: IV Congreso de Historia de la Corona de Aragón. Ponencias. Palma de Mallorca, 1955, pp. 185-207.

42 Madurell i Marumon, Josep M.; García SANZ, Arcadi: Comandas comerciales barcelonesas en la Baja Edad Media. Barcelona, 1973, 481 pp. 
tenido varias lecturas ${ }^{43}$, pero que en todo caso hacía poco aconsejable atracar naves mercantes en los puertos orientales. En cambio, la retención de las naves en el Mediterráneo occidental durante los diez años de lucha por la conquista de Nápoles no parece haber provocado más que una crisis momentánea; tampoco tuvo demasiada importancia la caída de Constantinopla, donde el comercio catalán era escaso. Más incidencia tuvo la política francesa de apoyo al puerto de Marsella: las especias traídas por los comerciantes catalanes desaparecieron del mercado de Tolouse en 1438. En todo caso, el golpe definitivo lo representó la guerra civil, pero en este punto tiene más razón Vilar que del Treppo: la guerra sale de la crisis. Por otra parte, la conciencia de crisis es clara ya en el parlamento de la reina María en las cortes de 1440: «El nombre de catalán, que era tenido en gran estima en todo el mundo, hoy apenas si se oye en levante ni en poniente». Las medidas proteccionistas fueron un paliativo económico insuficiente y un motivo de importantes enfrentamientos políticos. Que la guerra sale de la crisis y que ésta no era sólo catalana, sino del conjunto de la corona, puede afirmarse con otro argumento: si sólo la guerra fuese la causante de la crisis, Valencia o Mallorca habrían podido coger el relevo, cosa que no hicieron.

La guerra llevó la crisis a su cénit y dificultó la recuperación posterior, pero no hay que olvidar tampoco la dificultad añadida por el abatimiento del principal socio comercial catalán en oriente: Egipto, tan empobrecido que apenas significaba mercado para ningún producto que no fuese cobre o hierro; las compras debían saldarse mayoritariamente con moneda y los catalanes no disponían de capitales suficientes: la retirada a Rodas era estratégica, pero también económica 44 .

Riera y Feliu ${ }^{45}$ introducen una matización importante a la consideración general de los años que van de 1280-1285 a finales del siglo XV como una época de declive político y económico; sin poner en duda el atraso relativo, el marasmo político, ni la pérdida de vigor de la economía, se advierte que la producción, tanto agraria como manufacturera y puede que incluso el comercio, eran seguramente más elevados a finales del siglo XIV que a finales del XIII.

43 Aunque Coll atribuye al corso y la piratería las dificultades del comercio catalán, a partir de su descripción de los hechos sorprende lo rápidamente que se reanudaban las relaciones comerciales, salvo en el período 1438-1446 (COLL DE JULiÀ, Núria: «Aspectos negativos del tráfico marítimo en el siglo XV. Actos de piratería y consecuencias para el comercio internacional. Corsarios en las costas de la corona de Aragón», en $V$ Congreso de Historia de la Corona de Aragón. Vol. IV, Instituciones económicas, sociales y políticas de la época fernandina, Zaragoza, 1962, pp. 113-139). DEL TREPPO, Els mercaders..., p. 42-45, mantiene una visión mucho más optimista sobre los efectos del corso sobre el comercio.

${ }_{44}$ ASHTOR, Elihayu: «L'exportation de textiles occidentaux dans le Proche Orient musulman au bas Moyen Âge (1370-1517)». En Studi in memoria di Federigo Melis, vol. II. S.I., 1978, pp. 303-375, considera a los catalanes como la segunda potencia comercial en Egipto, sólo superada por Venecia.

45 RIERA, Antoni; Feliu, Gaspar: "Activitats econòmiques», en SObrequés, Jaume (dir.). Història de Barcelona. Vol. 3. La ciutat consolidada (segles XIV $i$ XV), Barcelona, (1992), pp. 137-272.

Hispania, LXIV/2, núm. 217 (2004) 435-466 
Así, por ejemplo, en 1390, momento según Vilar de dificultades, se decide la ampliación de las atarazanas, para que se pudiesen varar en ellas treinta galeras a la vez; por otra parte Barcelona disponía en la primera mitad del siglo XV de «una marina consistente y dúctil, bien organizada, veloz y omnipresente a lo largo de los principales ejes del comercio internacional», entre cuyos clientes figuraban a menudo mercaderes de otras ciudades. Por otra parte, durante la primera mitad del siglo XV, un $70 \%$ de las telas vendidas en Sicilia habían sido aportadas por mercaderes catalanes; $y$ hay que tener en cuenta la importancia estratégica de Sicilia en el comercio con Oriente. Otro factor positivo fue el aprovechamiento de la conquista de Nápoles, que permitió exportar a este mercado gran cantidad de paños, volver con alumbre y obtener un beneficio utilizable para saldar el déficit de la balanza con Oriente. También es entre 1428 y 1440 cuando se señala el mayor número de viajes hacia Flandes. Y entre 1440 y 1460 se observa un auge de la industria de la seda, que atrae a diversos maestros italianos. La conclusión es que, más que crisis, lo que se produjo fue un atraso relativo que después de la guerra resultaría imposible colmar.

Bajo el título «tiempo de expansión y tiempo de crisis», Belenguer realiza en primer lugar una amplia síntesis de la discusión sobre la crisis bajomedieval a nivel europeo ${ }^{46}$. Respecto a la crisis catalana, su esquema es básicamente el de Vilar. Sin embargo Belenguer destaca que se trata de dificultades, pero no de hundimiento y lo mismo puede decirse de los efectos de las múltiples iniciativas, a veces favorables y otras desfavorables, de Alfonso el Magnánimo, que en todo caso muestran claramente una situación a la defensiva y las dificultades y tanteos para encontrar caminos de recuperación. Finalmente, a la hora de entrar en el meollo de la crisis, Belenguer repite la disyuntiva Vilar - del Treppo, eludiendo entrar en la discusión del problema ${ }^{47}$.

En el mismo volumen, bajo el epígrafe «La economía: producir y comerciar», Paulino Iradiel ${ }^{48}$ ofrece una visión de la crisis para el conjunto de la Corona de Aragón que introduce aspectos de gran interés, como la constatación de que hasta bien entrado el siglo XV Cataluña mantuvo su posición privilegiada en el comercio internacional, reforzada por la comercialización de paños de producción propia, aunque participó poco en el comercio atlántico. Tampoco le parece apropiada la denominación de crisis general para la etapa 1380-1480, puesto que no queda demostrada por la evolución interna de los grandes sectores económicos, lo que no significa negar diversos momentos de dificultades,

46 Belenguer I CebriÀ, Ernst: «Temps d'expansió; temps de crisi», en BelenGUer CebriÀ, Ernest; CuAdrada, Coral (dirs.): La forja dels Països Catalans. Segles XIII a XV. Volum 3 de Riquer I PermanYer, Borja de (dir.): Història. política, societat $i$ cultura dels Països Catalans. Barcelona, 1996.

47 Por otra parte el examen conjunto de la crisis peca en algunos puntos de falta de información bibliográfica (o como mínimo no se considera oportuno ni siquiera comentar las nuevas aportaciones), especialmente en los aspectos monetarios y financieros.

48 IRAdiel, Paulino: «La economía: producir y comerciar», en BELENGuer y CuAdrada: La forja... pp. 96-99. 
como la crisis financiera de la década de 1380 , la caída de los ingresos públicos, que se reducen a cerca de la mitad entre 1390-1400 y 1430-1440, o el hundimiento del tráfico marítimo barcelonés, que en $1448-1456$ venía a ser una cuarta parte del observado en 1432-1434.

Su opinión es que la tesis de la crisis económica general presenta numerosos problemas, empezando por la pobreza de las fuentes cuantitativas y la hipervaloración de los efectos catastróficos de las pestes. En cambio habría que tener más en cuenta la escasa presión fiscal (que redunda en un estado «pobre») y el mantenimiento de una moneda fuerte: la moneda catalana se devaluó mucho menos que la mayoría de las monedas europeas. El punto más discutido de la crisis es la supuesta recesión del comercio internacional, que no parece haberse visto afectado por las coyunturas más críticas de principios y mitad del siglo $\mathrm{XV}$ y que además se veía reforzado por la venta de paños catalanes, sobre todo en el sur de Italia, lo que permitía asegurar el suministro de trigo siciliano; de hecho, el progreso de las técnicas comerciales resulta «irreconciliable con la tesis de la crisis del sistema económico global», al igual que la ampliación de los astilleros barceloneses. También debe matizarse, según Iradiel, la crisis agraria: no es seguro que la peste negra hiciese disminuir la producción y sin duda aumentó la productividad. Lo que si se produjo fue una disminución de la producción cerealícola, pero a cambio de la expansión de otros cultivos (azafrán, lino etc.) y de la ganadería; de hecho los precios de los cereales se mantuvieron por regla general bajos.

Coral Cuadrada ${ }^{49}$ repasa rápidamente las diferentes causas aducidas para explicar la decadencia económica catalana, para concluir que el tema tiene dos respuestas posibles: la decadencia general del Mediterráneo y la situación interna de Cataluña. En este último aspecto atribuye la decadencia a que la demanda interna, afectada por la desestructuración de la vida agraria, no pudo compensar las pérdidas o dificultades del comercio exterior ni hallar nuevos mercados sustitutorios. A la hora de fijar su postura sobre el punto más comprometido, los años 1430-1450, advierte que la extrapolación del comercio barcelonés al comercio catalán dificulta la comprensión del tema, pero no aporta ninguna explicación alternativa.

\section{CRECIMIENTO Y ATRASO}

Intentar poner al día el tema sólo puede hacerse (o al menos sólo puedo hacerlo) como reflexión a partir de las aportaciones de unos y otros, sin más pretensión que expresar una opinión, discutible, pero espero que no innecesaria, y sabiendo de antemano que las fuentes disponibles no nos permitirán segura-

49 CUADRADA MAjó, Coral: «Sobre les relacions camp-ciutat a la Baixa Edat Mitjana: Barcelona i les comarques de l'entorn", Acta Historica et Archaeologica Mediaevalia (Barcelona) 11-12 (1990-1991), pp. 161-185.

Hispania, LXIV/2, núm. 217 (2004) 435-466 
mente nunca contestar las preguntas básicas: ¿cuál fue la evolución de la productividad de los factores? ¿la mayoría de la población vivía mejor en 1480 que en 1280 ? No nos queda por tanto más remedio que movernos en un bosque de interrogantes; lo que pretendo es buscar un sendero para transitar por él.

Para ello, creo que en primer lugar es necesario distinguir entre decadencia y atraso: decadencia indica una caída en términos absolutos, atraso en términos relativos. Además, en ambos casos hay que distinguir entre los aspectos políticos y los económicos. En términos políticos, hubo sin duda decadencia: a pesar de la conquista de Nápoles, el poderío de la corona a mediados del s. XV (y mucho más a finales del mismo) era inferior al de finales del siglo XIII; y los mismo puede decirse de Cataluña en comparación al conjunto de la corona. El proceso a través del cual las autoridades aragonesas acabaron designando a los representantes de todos los reinos en el Compromiso de Caspe es buena muestra de ello.

Sin embargo, igual como el texto de Vilar que nos sirve de punto de partida, mi interés se centra especialmente en los aspectos económicos. En este sentido, mientras queda fuera de toda duda el atraso que a lo largo de la Baja Edad Media y en comparación a las economías concurrentes experimentó la economía catalana, la decadencia es mucho más discutible. Mi apuesta es que, si pudiésemos calcular el PIB catalán para 1300 y para 1500, éste último sería mayor en términos per capita. En cambio el crecimiento resultaría mucho menor que el de los países del entorno: Castilla, Francia, Génova o la misma Valencia, para no hablar de Flandes o Inglaterra. Como consecuencia de todo ello, Cataluña entró en la edad moderna con una pérdida definitiva de su estatus medieval en el conjunto de los países europeos. De hecho, la decadencia de Cataluña en la Baja Edad Media puede caracterizarse como un climaterio, un crecimiento desacelerado, comparable desde un punto de vista formal con el climaterio británico de finales del siglo XIX: en ambos casos, una situación de first comer (relativa) había proporcionado una ventaja, insostenible a la larga ante países de mayor potencial militar y económico. En este sentido, lo extraño no es el puesto de Cataluña en la jerarquía de potencias europeas al final de la Edad Media, lo anormal era la situación anterior ${ }^{50}$.

Aunque no resulta fácil en la práctica, conviene distinguir en teoría entre crisis estructurales (depresiones) y crisis coyunturales; p.e., el peor y más decisivo momento de la decadencia catalana es sin ninguna duda la guerra civil; se trata, sin embargo, de una crisis claramente coyuntural: sin los episodios en torno a Carlos de Viana, los grupos oligárquicos no habrían conseguido el fermento antimonárquico para enfrentarse al rey ${ }^{51}$. La importancia de la guerra

\footnotetext{
so Algo parecido valdría para la «decadencia» de la monarquía española en los siglos XVII y XVIII.

${ }^{51} \mathrm{La}$ guerra civil tiene su origen en el encarcelamiento del príncipe heredero, Carlos de Viana, enfrentado a su padre, que se negaba a entregarle el trono de Navarra. En el trasfondo estaban las maniobras de la nueva esposa del rey, Juana Enríquez, para substituir al hijastro por su hijo Fernando (el Católico), o sea la situación clásica de hombre viejo enamorado de mujer joven y manejado
} 
civil no radica en ella misma, sino en el impacto que una crisis coyuntural fuerte representó sobre una larga crisis estructural, sobre una fase de depresión.

Para analizar la depresión económica es útil, a mi entender, distinguir cinco esferas, de las que cuatro son relativamente autónomas entre si, en el sentido de que los cambios que sufren tienen relativamente poca incidencia sobre los demás. Dichas esfera son el sector agrario, la producción urbana, el comercio exterior y las finanzas; en cambio la quinta esfera, la política económica, a la vez depende del resto e influye sobre ellas.

\section{El campo y la cuestión agraria}

El campo catalán experimentó importantes y dispares transformaciones como consecuencia de la Peste Negra. Por muchas críticas que se puedan hacer a los fogajes y al resto de indicadores ${ }^{52}$, no hay ninguna duda seria sobre la caída de la población catalana a lo largo de la Baja Edad Media.

Más complejo es dilucidar la relación de ésta disminución de la población con la decadencia económica. Aunque podríamos considerar otros aspectos, creo que lo importante es tener presente que en una situación de «mundo lleno» ${ }^{53}$, la caída de la población tiene un efecto positivo sobre la productividad (disponibilidad de tierras suficientes, concentración del trabajo en las tierras mejores) y un efecto negativo sobre las rentas ${ }^{54}$. Sin embargo, puesto que el repartimiento final de la población parece haber provocado una mayor pérdida en el campo que en la ciudad, cabría interrogarse sobre si la caída de la producción creó dificultades para el abastecimiento urbano. A juzgar por la tendencia a la baja de los precios de los cereales"s, parece que la producción fue suficiente para alimentar, en años normales, una población disminuida. En el mismo sen-

por ella. Por norma, el heredero era el lugarteniente del rey en Cataluña, por lo que la Generalitat protestó por el encarcelamiento de Carlos de Viana y levantó un ejército para impedir la entrada del rey en Cataluña, con lo que logró que el príncipe fuese repuesto en su cargo. Pero su muerte en Barcelona al cabo de pocos meses (con sospechas de haber sido envenenado) y el nombramiento como lugarteniente de Juana Enríquez (como tutora del príncipe Fernando) precipitó el enfrentamiento.

52 Sobre los fogajes puede verse, como trabajos más recientes, FeliU, Gaspar: «La demografia baixmedieval catalana: estat de la qüestió i propostes de futur» en CRUSELLES, Enrique (coord.) La población urbana en tienpos de crisis. Revista de Història medieval (Valencia) 10 (1999) pp. 13-43; y REDONDO GARCíA, Ester: El fogatjament general de Catalunya de 1378, Barcelona, 2002, esp. pp.5-23.

53 SALRACH» La Corona...», p. 314.

54 IRADIEL: «La economía...».

ss Esto es lo que parece deducirse de la serie de Lérida (ARGILÉs I ALUJA, Caterina: «Evolució dels preus lleidatans a la Baixa Edat Mitjana (1362-1500)", Butlletí de la Societat Catalana d'Estudis Històrics (Barcelona) 6 (1995) pp. 21-59. La disminución del precio de los cereales se enmarca en una tónica general de decenso de precios, sin que sepamos lo suficiente de la evolución de éstos para afirmar si los campesinos experimentaron o no un empeoramiento de sus términos de intercambio. Por otra parte hay que tener en cuenta que, tanto antes como después de la crisis, no se trata sólo de la oferta catalana, sino también de la de las zonas próximas, como Aragón o Sicilia:

Hispania, LXIV/2, núm. 217 (2004) 435-466 
tido puede interpretarse la introducción o ampliación de cultivos comerciales no alimenticios, como el vino, el aceite, los frutos secos, el lino, el cáñamo y, por encima de todo, el azafrán. Por otra parte, la caída de precios fue general y por tanto no afectó de forma especialmente negativa a los campesinos. Tampoco los cambios experimentados en el seno del campesinado parece que deban atribuirse en principio a la crisis; ciertamente los beneficiarios fueron la primera generación de supervivientes, que pudieron aumentar sus explotaciones y/o bien obtener tierra en condiciones más favorables. Luego la costumbre de la herencia única y los avatares normales de cualquier economía campesina hizo crecer el número de desheredados y la diferenciación social en el seno del campesinado. Pero, en conjunto, parece difícil sostener que los campesinos viesen agravada su situación como consecuencia de la caída demográfica y que ésta y la consiguiente disminución de la producción puedan considerarse el primer motor de la crisis, con efectos a largo plazo sobre el conjunto de la economía.

Igualmente debe considerarse si la caída de la población rural pudo ser un factor de crisis a través del descenso de la demanda de productos procedentes de la ciudad, puesto que en éste caso sí cabría establecer una relación de causa efecto entre la disminución de la población y la crisis de la manufactura urbana. Es posible que algunas villas-mercado sufriesen algo en este sentido, aunque el descenso del número de compradores podía acompañarse de la disminución por las mismas razones del número de artesanos y además el menor número de compradores podía compensarse con una mayor capacidad individual de compra. En cambio es muy dudosa la relación respecto a la manufactura urbana, para la que el mundo rural no era, ni mucho menos, un mercado básico.

Los aspectos más negativos de la disminución de la población fueron sin duda la escasez de gente para poblar las nuevas conquistas ${ }^{56}$, en especial Cerdeña (1354-1355), lo que dificultó y encareció el dominio de la isla, teatro de repetidas sublevaciones. La repercusión más importante de la caída de la población fue el aumento de la presión fiscal, pero este punto no depende directamente del número de los hombres, sino de la política económica de la monarquía.

En definitiva, en mi opinión, la caída de la población y la evolución de la producción agraria pueden considerarse como elementos practicamente neutros a efectos económicos: no se produjo desabastecimiento, ni aumento de precios ni graves pérdidas de capital comercial; por tanto, sin llegar a la contundente afirmación de Guilleré, quien afirma que considerar el descenso demográfico como causa esencial de la crisis del siglo XV es «un mito más», ${ }^{57}$ creo que Vilar y sus seguidores posteriores van demasiado lejos al retrotraer la crisis hasta el mal any primer (1333) o la Peste Negra.

56 RENOUARD, Yves: «Les principaux aspects économiques et sociaux de l'histoire des pays de la couronne d'Aragon aux XII ${ }^{e}, \mathrm{XIII}^{\mathrm{e}}$ et $\mathrm{XIV}^{\mathrm{e}}$ siècles», en VII Congreso de Historia de la Corona de Aragón. Ponencias, Barcelona, 1962, pp. 229-264. Reeditado en RENOUARD, Yves: Etudes d'bistoire médiévale, París, 1968, II vol., vol. I, pp. 1083-1112; la cita es de esta edición, pp. 1102-1103.

s7 GuILLERÉ, C., Girona al segle XIV. Barcelona,1993, II vol., 504 y 500 pp. 
Con todo, la posible "edad de oro del campesinado" se vio pronto oscurecida por diversos factores. El aumento de impuestos ${ }^{58}$ y la disminución a la vez de la población, la producción y los precios multiplicaron la presión fiscal real, incrementada por el endeudamiento, tanto personal como municipal. Las concesiones fiscales de la cortes eran satisfechas mediante la venta de censales por parte de la Generalitat y lo mismo hacían a menudo los municipios, ante la imposibilidad de recaudar grandes sumas con la rapidez exigida. El aumento de la deuda llevó incluso al abandono de muchos lugares: es sintomático que los despoblados no aparezcan tanto en los años posteriores a la peste como en el siglo $\mathrm{XV}^{59}$.

Por otra parte, la clase feudal reaccionó ante el hundimiento de las rentas agrarias intentando, al cabo de una generación (hacia 1380-1385), deshacer los pactos concedidos tras la peste, iniciando así el conflicto remença con la lucha por los masos rònecs ${ }^{60}$. Las diversas fases del enfrentamiento, que duró un siglo casi exacto (1385-1486), provocaron muertes y destrucciones y costaron a señores y campesinos fuertes sumas, necesarias para mantener la lucha y en especial para propiciarse el favor real. Peor aún, el problema remença fue uno de los dos componentes principales de la guerra civil y el responsable de su larga du-

58 La creación de la fiscalidad de estado y sus repercusiones sobre la fiscalidad municipal es seguramente el aspecto más innovador de la historiografía medieval catalana de la última década (TURULl, Max: «La Hacienda municipal y la tributación directa en Cataluña durante la Edad Media. Planteamiento general», en Revista de Hacienda Autonómica y Local (Madrid) XXII/64 (1992), pp. 9-80; SÁNCHEZ MARTÍNEZ, Manuel: El naixement de la fiscalitat d'Estat a Catalunya (segles XIIXIV), Vic, 1995, 147 pp.; SÁNCHEZ MARTÍNEZ, Manuel: «Fiscalidad y finanzas municipales en las ciudades y villas reales de Cataluña» en Finanzas y fiscalidad municipal. $V$ Congreso de estudios medievales, Valladolid, 1997, pp. 207-238; Ortí Gost, Pere; SÁNCHEZ MARTínEZ, Manuel; TuRULl RubINAT, Max: «La génesis de la fiscalidad municipal en Cataluña», en FuRIÓ, Antoni (coord.): La gènesi de la fiscalitat municipal (segles XII-XIV). Revista d'Història Medieval (Valencia) 7 (1996), pp. 115 134; TURUll RuBINAT, Max: «Fiscalitat a l'època medieval» en III Congrés Internacional d'bistòria local de Catalunyua. Funcionament de les finances locals al larg de la història, Barcelona, 1996, pp. 23-55; SÁNCHEZ, Manuel; FurIó, Antoni (comp.): Actes del Col-loqui "Corona, Municipis i Fiscalitat a la Baixa Edat Mitjana, Lleida, 1997, 705 pp; SÁNCHEZ, Manuel (ed.): Fiscalidad real y finanzas urbanas en la Cataluña medieval. Barcelona, 1999, 399 pp.; Furıó, Antoni: «Deuda pública e intereses privados. Finanzas y fiscalidad municipales en la Corona de Aragón», en Edad Media, Revista de Historia (Valladolid) 2 (1999), pp. 35-79; ORTí, Pere: Renda i fiscalitat en una ciutat medieval: Barcelona, segles XII-XIV. Barcelona, 2000, 736 pp.; MORELLÓ BAGET, Jordi: Fiscalitat $i$ deute públic en dues viles del Camp de Tarragona, Reus i Valls, segles XIV-XV. Barcelona, 2001, 1007 pp.; ORTí, Pere: «La primera articulación del estado feudal en Cataluña a través de un impuesto: el bovaje (ss. XII-XIII)» en Hispania (Madrid) 209 (2001), pp. 967-998.

59 Puesto que el endeudamiento es colectivo, un pueblo puede despoblarse si sus hogares descienden por debajo de un punto crítico que hace imposible a sus habitantes hacer frenta al pago de las pensiones de los censales.

$60 \mathrm{O}$ sea los mansos deshabitados tras la peste y unidos a los mansos vecinos en condiciones favorables para los cultivadores. Con la excusa de que no se cumplía el afocament o sea tener hogar en el manso, los señores pretendían recuperar la posesión de los masos rònecs. 
ración; por lo tanto, aunque tardía e indirectamente, fue un factor de peso en el hundimiento definitivo de la economía catalana, pero con escasa incidencia hasta la segunda mitad del siglo XV.

\section{El sector urbano}

En lo que respecta a la producción urbana, conviene tener en cuenta en primer lugar que tras la Peste, Barcelona no parece haber perdido población, ${ }^{61}$ aunque en la etapa posterior el crecimiento fue muy lento e incluso hubo momentos de estancamiento: sólo la guerra civil hizo disminuir la población de la ciudad, como se observa claramente en el recuento de $1497^{62}$, aunque la caída de la población barcelonesa es muy inferior a la que experimenta el conjunto del territorio catalán. En cambio sí sufrió un fuerte descenso la población de Gerona $^{63}$ y la de Manresa ${ }^{64}$.

Respecto a la actividad económica, Riera y Feliu ${ }^{65}$ ponen de relieve que en Barcelona se produjo alrededor de 1300 un cambio de orientación importante: el comercio exterior, que hasta entonces había consistido básicamente en el tráfico de artículos de lujo y de productos agrarios de primera necesidad, se articuló en adelante con la manufactura urbana y constituyó un importante factor de crecimiento de ésta. Aunque se trata de un indicador muy grosero, la multiplicación del número de gremios (generalmente a través de un proceso de especialización - escisión) puede dar una primera idea de la vitalidad del sector secundario barcelonés: los diecinueve gremios representados en el municipio a finales del siglo XIII, eran treinta y dos en 1325 y cuarenta y cinco en 1395 . En el mismo sentido se puede interpretar la amplia importación de esclavos, a menudo destinados a oficios especializados, escasos en mano de obra, como calafates, corderos, tejedores o incluso pintores y escultores ${ }^{66}$. El indicador más claro es sin embargo el fiscal; según Carrère ${ }^{67}$, el $75 \%$ de los ingresos fiscales de la Generalitat en la primera mitad del siglo XV pocedían de la industria pañera.

\footnotetext{
${ }^{61}$ GuÀrdia y García ESPUCHE: «Consolidació...», p. 38.

${ }^{62}$ VICENS VIVES: Els Trastàmares..., p. 11 habla inçluso de una recuperación bastante satisfactoria de la población urbana entre 1400 y 1450, pero las bases documentales para el aserto son muy débiles.

${ }^{63}$ Alberch I Fugueras, Ramon; CASTells I CAlZADA, Narcís: La població de Girona (segles XIV-XX), Gerona, 1985, 184 pp., esp. P. 17; de hecho, la población de 1360 no se volvería alcanzar hasta el siglo XVIII.

${ }^{64}$ TORRAS I SERRA, Marc: La crisis del segle XV a Manresa. Una aproximació a partir dels llibres de manifests, Manresa, 1996, 139 pp., esp. p. 57.

${ }^{65}$ RIERA Y FELIU: «Activitats...», p. 149.

66 SALICRÚ I LLUCH, Roser: Esclaus i propietaris d'esclaus a la Catalunya del segle XV. L'assegurança contra fugues, Barcelona, 1998, 225 pp.; FerRer I MALlol, Maria Teresa; MUTGÉ I VIVES, Josefina (eds.): De l'esclavitud a la llibertat. Esclaus i lliberts a l'Edat Mitjana. Actes del Col-loqui Internacional celebrat a Barcelona, del 27 al 29 de maig de 1999, Barcelona, 2000, 751 pp.

${ }^{67}$ CARRÈRE: «La draperie..., p. 475.
} 
Otro indicador posible, la evolución del salario real, tampoco parece abogar a favor de la crisis, aunque la única comparación que podemos llevar a cabo sea un tanto marginal: el salario trigo de los canteros de la catedral de Lérida ${ }^{68}$ muestra un ascenso continuado hasta la década de 1441-1450 y un ligero bache en las dos décadas posteriores (1451-1470), para recuperarse a continuación.

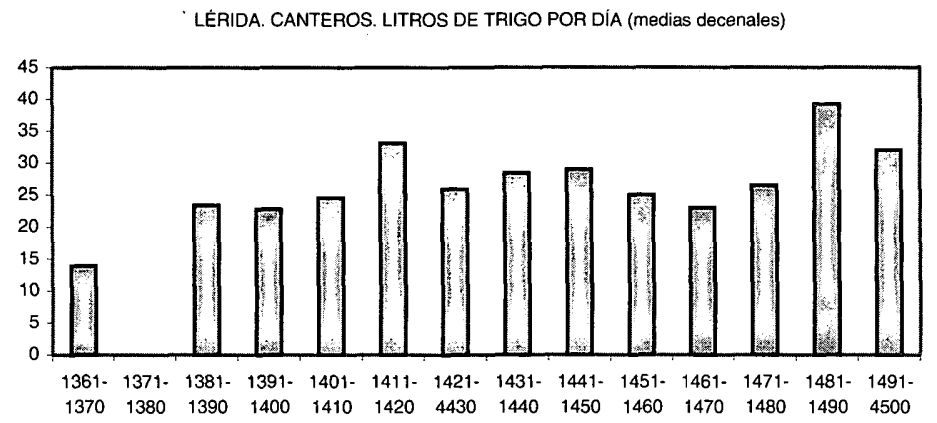

Fuente: elaboración propia a partir de ARGILÉS: «Evolució dels preus...», P. 43-46.

Los sectores más activos en las actividades destinadas a la exportación fueron el cuero, el coral y sobre todo el textil: fustanes, seda, paños de lana, con la imitación, a partir de 1298, de tejidos flamencos de calidad media, que serían el gran producto de exportación de la pañería barcelonesa ${ }^{69}$; en cambio el intento, a partir de 1436, de imitar los tejidos de calidad flamencos e ingleses, no logró un producto suficientemente competitivo en los mercados internacionales. Hay que tener en cuenta sin embargo, que la producción textil, incluso la destinada a la exportación, contaba con diversos centros, incluso en áreas rurales ${ }^{70}$.

En definitiva, a pesar de la decadencia de algunas actividades, no parece que se pueda hablar de depresión en la producción manufacturera barcelonesa antes de la guerra civil. Según Fernández Trabal ${ }^{71}$, en Gerona la producción artesana se mantuvo, a pesar de la crisis de la ciudad, muy evidente a partir de 1380 , que se debió al hundimiento del comercio y de la banca. También en Manresa se observan signos de crisis, pero no antes del segundo tercio del siglo $\mathrm{XV}^{72}$.

\footnotetext{
68 ARGILÈs: «Evolució dels preus...», p. 43-46.

69 BRESC, Henri: «La draperie catalane au miroir sicilien, 1300-1460" en Acta Historica et Archaeologica Mediaevalia (Barcelona) 4 (1963), pp. 107-127, esp. p. 110.

70 ASHTOR: «L'exportation...», p. 332-333.

71 Fernández TRABAL, Josep: Una família catalana medieval. Els Bell-lloch de Girona, $1267-$ 1533. Barcelona, 1995

72 TORRA, La crisi...

Hispania, LXIV/2, núm. 217 (2004) 435-466
} 


\section{El comercio exterior}

Tanto la economía agraria como la economía urbana eran importantes. Sin embargo, el comercio exterior, que era la actividad que proporcionaba las mayores ganancias, era también el sector cuyas crisis, que además solían ser más súbitas e impredecibles, solían tener mayores repercusiones. Un aspecto importante del comercio exterior, sobre todo de tejidos, era que en gran parte estaba asegurado por comerciantes catalanes. ${ }^{73}$ No hay que olvidar sin embargo que el comercio exterior se componía de diversas zonas, articuladas pero independientes, y que por tanto los problemas que afectaban en determinados momentos determinadas rutas o productos podían paliarse con una mayor atención a otros. Con todo, el comercio con Oriente fue siempre, sin duda, «foment, cap e principi de tot negoci» ${ }^{74}$ y fue también por ello la principal causa estructural de la depresión catalana en particular y del mundo mediterráneo en general.

Tanto en términos absolutos como relativos, no se puede dudar de la importancia del comercio con Oriente ni de su crecimiento a lo largo de la Baja Edad Media, al menos hasta la guerra civil: a pesar de todo tipo de contingencias, la tendencia fue creciente, tanto el número de viajes como el volumen y valor de los productos intercambiados. Tampoco cabría hablar de crisis en términos relativos: Barcelona fue claramente, hasta 1462 la tercera potencia en el comercio con oriente, tras Venecia y Génova ${ }^{75}$.

La depresión no era evidente ni tampoco radicaba en aspectos que podamos cifrar; de ahí la dificultad para detectarla y en especial para fijarla en el tiempo. El problema no era de volumen de negocio, sino de beneficios y éstos fueron en conjunto decrecientes, por tres grupos de razones: la disminución de la capacidad de transporte, la degradación de la situación en el Mediterráneo oriental y la competencia en occidente. En el caso del comercio exterior cabe hablar más de decandencia (caída de beneficios) que de atraso (pérdida de peso relativo), salvo quizá en la segunda mitad del siglo XV en comparación con Marsella, benficiada de la eficiente protección e la corona francesa.

Vicens Vives ${ }^{76}$ señala la decadencia de la marina catalana como una de las causas importantes de la crisis: a la sangría de naves y tripulaciones preparadas que habían significado las luchas contra Génova y Venecia entre 1390 y 1410 hay que añadir los enfrentamientos durante la conquista de Nápoles, en especial la funesta jornada de Ponza, y la competitividad de las naves atlánticas,

73 CARRÈRE, «La draperie...", p. 490.

74 CAMPMANY Y DE MONTPALAU, Antonio de: Memorias históricas sobre la marina, comercio y artes de la antigua ciudad de Barcelona, IV vol., Madrid 1779-1792, (Reeditada en Barcelona, 1961-1963), vol. IV, doc. 124.

75 AsHTOR, «L'exportation...» p. 374-375; BALARD, Michel: «Marchés et circulation monétaire en Méditerranée orientale (XIII $-\mathrm{XV}^{\mathrm{e}} \mathrm{s}$.), en Moneda y monedas en la Europa medieval (siglos XII-XV). XXVI Semana de Estudios Medievales. Estella, 19 a 23 de julio de 1999. Pamplona, 2000, p. 273.

76 VICENS VIVES: «Evolución de la economía...», p. 193-194. 
más pequeñas y maniobrables, que acaparan sobre todo el comercio de cabotaje. Hay que tener en cuenta que el coste de los fletes llega a veces a igualar el de los productos transportados, por tanto su pérdida es un factor importante de disminución del negocio ${ }^{77}$; sin embargo, la visión de Vicens, excesivamente pesismista, ha de matizarse con el mejor conocimiento de la construcción naval tras el trabajo de Riera ${ }^{78}$.

En oriente, la etapa de guerras y destrucciones que provocó la reconstrucción del imperio mongol por Tamerlán (a partir de 1370) y las luchas que a su muerte acompañaron la desintegración de su imperio, con la destrucción de la ruta de la seda y la implantación en Egipto de los mamelucos, significaron la ruina del proximo oriente y crecientes dificultades para el comercio ${ }^{79}$. De hecho, durante la mayor parte del siglo XV las relaciones directas con los puertos de Siria y Egipto fueron imposibles o peligrosas, de manera que la mayoría de las naves catalanas no pasaban más allá de Rodas o de Chipre; el volumen exportado podía ser el mismo o superior, pero es evidente que la introducción de intermediarios, la pérdida de cargamentos e incluso de naves enteras, o el coste superior de los seguros, tenían que significar una disminución importante del beneficio ${ }^{80}$.

Y lo mismo sucedía en occidente: el papel de redistribuidor de productos orientales que los catalanes ejercían hacia el interior de la península y el sur de Francia fue roído por el aposentamiento de los genoveses en Sevilla y por las medidas proteccionistas de la monarquía francesa. Los productos continuaban viajando a través de la ruta del Ebro hacia la meseta o por mar hacia Sevilla, pero la competencia genovesa representaba una disminución de las ventas y unos precios menos remunerativos en Sevilla; y por otra parte la larga guerra con Castilla (1356-1369) interrumpió o dificultó a menudo el comercio, todo lo cual se aunaba para rebajar los beneficios ${ }^{81}$. Por su parte, los productos desembarcados en los puertos franceses debían enfrentarse a la doble competencia de los derechos de aduana y del renacido y protegido comercio marsellés. En ambos casos, a menudo eran comerciantes extranjeros quienes adquirían en Sicilia o en los puertos catalanes los productos que estos traían de oriente y se ocupaban de la última etapa de su comercialización. Tambien en Flandes, el comercio catalán parece entrar en decadencia a partir de este momento ${ }^{82}$ : mientras el consulado catalán pagaba en 1378-79 igual que las «naciones» más

77 BALARD: «Marchés...», p. 273.

78 RIERA MELIS, Antoni: «La construcció naval a Catalunya a les vespres dels grans descobriments geogràfics» en Revista de Historia Medieval, (Valencia) 3 (1992), pp. 55-78.

79 AsHTOR, «L'exportation...» p. 305.

80 FELIU: «El comercio...» pp. 700-701.

${ }^{81}$ DufourCQ y GaUTIER-DALCHÉ: L'Espagne..., p. 274

82 Para el comercio con Flandes puede verse RIERA y FelIU: «Activitats...», p. 217-221 y DesPORTES BIELSA, Pablo: «El consulado catalán de Brujas (1330-1488)», en Aragón en la edad media (XIV-XV). Homenaje a la profesora Carmen Orcástegui Gros. Vol. I. Zaragoza, 1999, p. 375-390.

Hispania, LXIV/2, núm. 217 (2004) 435-466 
ricas (Florencia, Venecia y Plasencia), en 1411-1412 pagó la segunda cuota, un $20 \%$ menos que los genoveses, aunque más que el resto ${ }^{83}$. La decadencia fue clara a partir de 1440 , tras unos incidentes que representaron la imposición de gravámenes extraordinarios a los comerciantes catalanes. Muestras de decadencia clara son también el cambio de nombre, a finales del siglo XV, de consulado de los catalanes a consulado de los aragoneses, en aquel momento tanto o más numerosos ${ }^{84}$.

Disminuído por ambos extremos, el comercio con oriente ya no proporcionaba los beneficios de la etapa de esplendor; podía haber coyunturas más o menos favorables, pero la espina dorsal de la prosperidad catalana se había roto para siempre. Podemos fijar algunos hitos: a partir de 1370, las conquistas de Tamerlán hicieron imposible la ruta de la seda, liquidaron las colonias genovesas en el mar Negro y ahogaron la economía de Bizancio; en 1401 el incendio y destrucción de Damasco fue un duro golpe para el comercio catalán ${ }^{85}$, en 1408 se produjo el primer conflicto con el sultán de Egipto ${ }^{86}$. Aunque la etapa de esplendor se mantuvo hasta 1462, el ritmo de crecimiento se quebró en algún momento entre 1380 y 1415.

Dado el papel central y motor del comercio con oriente para la economía catalana, me inclino a situar en estos años a caballo entre el siglo XIV y el XV el momento de inflexión, el inicio de la depresión; en todo caso, no más tarde de 1415. A partir de este momento, algunos se aferrarán al viejo negocio, mientras otros empiezan a explorar nuevos caminos: quienes habían conseguido rentas suficientes optaron por la compra de tierras o de censos, los recién llegados confiaron en la producción y exportación de productos propios y en la intensificación del comercio con el Mediterráneo occidental y el Atlántico.

A lo largo del siglo xv se produjeron repetidos acontecimientos negativos que, sumados, señalan el declinar definitivo del comercio catalán con oriente. Con pocos años de diferencia, se hizo notar una escasez de naves, retenidas por Alfonso el Magnánimo en el Mediterráneo occidental, en la lucha por la conquista de Nápoles, muchas de las cuales se perdieron en batallas navales como la de Ponza (1435), el cierre de los mercados del sur de Francia a las especias traídas por los catalanes y la caída de Constantinopla (1453).

Las medidas proteccionistas que la monarquía intentó poner en pie estos mismos años son sin duda buena muestra de la conciencia de dificultades que experimentaba el comercio catalán. Pero la base principal de la crisis era exógena y profunda: como señala Ashtor, el Egipto de los mamelucos estaba tan arruinado que apenas tenía capacidad de compra. Con ello desaparecía el mercado para los paños catalanes, y por tanto la crisis se trasladaba también a la

\footnotetext{
83 DESPORTES: «El consulado...», p. 382.

${ }^{84}$ DESPORTES: «El consulado...», p. 381.

85 MAdurell y García SANZ, Comandas..., p. 28-29.

86 DEL TREPPo, Els mercaders, p. 42.
} 
manufactura urbana: las compras se habían de saldar en gran parte con moneda; sólo Venecia podía resistir estas condiciones ${ }^{87}$. Sin embargo, a pesar de la crisis y de la guerra, el recuerdo de los buenos años del comercio con oriente fue perdurable, aunque irrepetible: de 1477 a 1503, se realizaron 31 viajes ( 3 de ellos en naves extranjeras), poco más de un viaje por año.

Igualmente, como ha quedado dicho, fueron causas políticas las que apartaron a los catalanes de Sevilla, en provecho de los genoveses, como lo eran las que habían permitido, a la inversa, la substitución de los genoveses por los catalanes en Sicilia en los primeros años de Alfonso el Magnánimo y la que les dieron luego privilegios en Nápoles, aunque tales privilegios fueron cada vez más papel mojado ante la connivencia de los gobernadores castellanos colocados por Alfonso el Magnánimo al frente de Sicilia y luego de Nápoles, con los comerciantes genoveses y florentinos ${ }^{88}$.

\section{La crisis monetaria i financiera}

La crisis financiera, es con la decadencia del comercio con oriente, el otro pilar principal de la crisis; las finanzas catalanas nunca se recuperaron de la serie de quiebras de 1381-1383; no tanto por el montante del capital perdido (en gran parte lo que dejó de pagar el rey eran intereses altamente usurarios), ni porqué, contra lo que suponía Vicens Vives ${ }^{89}$, las pérdidas afectasen demasiado al capital comercial: no hay ningún nombre repetido entre la lista de acreedores de la banca de Pere des Caus y Andreu d'Olivella, que he podido rehacer, y los nombres que aparecen en los índices de las obras sobre comandas comerciales o sobre seguros y cambios marítimos ${ }^{90}$ : el comercio y la renta se movían en espacios diferentes. Lo importante de la crisis fue la pérdida de confianza en las casas de banca y su substitución por banqueros extranjeros, principalmente italianos.

La crisis financiera es una primera señal de alarma ante la cual las autoridades reaccionaron reforzando el aparato institucional mercantil, en especial el Consolat de mar, en su triple vertiente de código, tribunal mercantil y organismo responsable de la representación consular. Obra de este momento es también la creación de la Taula de Canvi de Barcelona, primer banco público de Europa (1401), ${ }^{91}$ considerada por Vicens Vives como una solución miope y a la defensiva, muestra de la pérdida de vigor empresarial e indicio por tanto de

\footnotetext{
87 FELIU: «El comercio...», p. 703.

88 BRESC: Un monde... p. 727 y 849.

89 VICENS VIVES: Els Trastàmares..., p. 18.

90 Madurell y García Sanz: «Comandas...; García Sanz, Arcadi; Ferrer Mallol, Maria Teresa: Assegurances i.canvis marítims medievals a Barcelona, Barcelona, 1983.

91 Adroer, Anna M.; Feliu, Gaspar: Història de la Taula de Canvi de Barcelona. Barcelona, 1989, 111 pp.

Hispania, LXIV/2, núm. 217 (2004) 435-466
} 
decadencia, dado que apartaba capitales de la circulación para depositarlos en una institución ajena al crédito mercantil ${ }^{92}$. Vilar es menos crítico: en su opinión la Taula fue sobre todo una garantía contra el aumento de la deuda municipal y contra la inestabilidad de los bancos privados ${ }^{93}$. A mi parecer, la Taula fue un instrumento útil y adecuado, que ayudó más que perjudicó a la marcha de la economía ${ }^{94}$.

El punto polémico son los depósitos a solta, retenidos en la Taula mientras no se cumpliese determinada condición (desde una sentencia judicial a una mayoría de edad o el cumplimiento de un contrato). Las alternativas eran que continuasen en manos de notarios o banqueros privados, quienes ciertamente podían usarlos en provecho propio para sus negocios (directos o a través del crédito), pero con ello el titular del depósito se exponía a posibles pérdidas sin la contrapartida de participación alguna en las ganancias; o bien que se depositasen a buen resguardo en la Taula y sirviesen para disminuir la deuda de la Ciudad. En realidad, contra lo que podría suponerse, la Taula disminuía la deuda pública, puesto que utilizaba parte de los capitales en depósito para devolver censales, de manera que, al menos en este aspecto, no beneficiaba el «rentismo». En cambio, al disminuir la carga de la deuda, permitía evitar el alza de impuestos. En definitiva, la Taula evitaba los riesgos del capital mercantil a quienes no tenían ninguna intención de participar en negocios ni ninguna ganancia en que su capital fuese utilizado y puesto en peligro por terceros.

Quedaría un último punto a dilucidar, pero en este momento no puedo pasar del planteamiento de la pregunta; ¿qué porcentaje del capital barcelonés significaban los depósitos forzosos? El 1396 la deuda municipal ascendía a 386.963 libras catalanas; en 1420-29, había disminuido hasta 125.000 libras. Suponiendo que la diferencia se hubiese obtenido mediante la luición de censales, ${ }^{95}$ estas 262.000 libras rebajadas vendrían a ser aproximadamente una octava parte del tráfico comercial sometido al pago de los derechos de entrada en el puerto (periatge).

Respecto a la crisis monetaria, sigue repitièndose la explicación de Vilar: «la crisis del Principado señalada por el fracaso de un signo monetario de tenor metálico elevado: era del croat, era del florín»: el croat de plata había sido la moneda de un período de contínua expansión; con la creación del florín de oro, Pedro el Ceremonioso materializa una esperanza excesiva, lo que lleva la pieza a perder rápidamente contenido oro: en 1365 ha perdido una cuarta parte respecto al florín de 1346, aunque luego se mantuviera estable cerca de un siglo. Vilar trata luego el problema de la ratio entre el oro y la plata: fijada muy alta en Cataluña, expulsa la moneda de plata, que es substituída por moneda fran-

92 VICENS VIVES, Els Trastàmares..., p. 18.

93 VILAR, Catalunya..., p.

94 ADROER y Feliu: Història..., p. 31. FeliU: «Moneda...», p. 132.

95 En realidad, puesto que se trataba de un momento de relativa prosperidad, debía deberse en parte al aumento de los ingresos. 
cesa, de menor contenido. A ello se une la polémica sobre si convenía o no devaluar la moneda ${ }^{96}$, que enfrenta rentistas e importadores (la biga) con artesanos y exportadores (la busca). Vilar interpreta todo ello acertadamente más como «expresión» que como "causa» de la crisis ${ }^{97}$. Sin embargo su análisis es erróneo en algunos puntos básicos.

Los trabajos de Crusafont son en este aspecto definitivos ${ }^{98}$ : el problema de la valoración del croat es el resultado del empeño del municipio barcelonés en mantener intocable el dinero de plata, doce de los cuales equivalían en peso y valor a un croat. Pero acuñar doce dineros es más caro que acuñar un croat, por lo que se batían pocos dineros y una renovación escasa hacía que el numerario circulante, desgastado por el uso, resultase corto de peso: mantener la paridad exigía aumentar la relación $1 / 12$ entre el dinero y el croat $^{99}$. Las autoridades barcelonesas fueron incapaces de entenderlo, pero esto no tiene nada que ver con decadencia o crisis, aunque si comportaba los problemas inherentes a la introducción de monedas forasteras.

Por lo que respecta al florín, el problema era también puramente numismático: había sido aforado a 11 sueldos, lo que daba una ratio excesivamente baja, que provocaba la salida de plata ${ }^{100}$. Las sucesivas disminuciones del contenido oro del florín, aparte del beneficio de la monarquía, buscaban equilibrar la ratio sin confesarlo públicamente. En el gran enfrentamiento en torno a la moneda entre 1430 y 1450 , todos estaban de acuerdo en elevar el foro del croat, pero mientras la biga proponía 15 dineros, la busca pensaba en 18, elevando al mismo tiempo el florín a 13 sueldos: con ello se reequilibraba la moneda catalana tanto entre el oro y la plata como en su contexto internacional; pero revalorar el croat y el florín en moneda de cuenta significaba rebajar el valor real de las rentas escriturarias, que era a lo que se oponía la biga ${ }^{101}$. Como dice Crusafont (1996), la cuestión era, en definitiva, quien pagaba la crisis ${ }^{102}$. Precisamente la batalla en torno a las rentas afectaba a los libros contables de los banqueros, pero muy en especial los de la Taula de Canvi: los rentistas

\footnotetext{
${ }^{96}$ Lo que se intenta devaluar es el dinero, a la vez moneda real básica y moneda de cuenta. Por tanto la devaluación del dinero significa un aumento del número de dineros que equivalían a un croat o un florín.

97 VILAR: Catalunya... vol. II p. 176.

98 Crusafont i Sabater, M.: Barcelona y la moneda catalana. Barcelona, 1989, 244 pp; CRUSAFONT I SABATER, M., Història de la moneda catalana. Barcelona, 1996, 205 pp.

99 La alternativa teórica, disminuir el peso del croat, ni siquiera se planteaba.

100 Feliu, Gaspar: «Moneda y banca en Cataluña en el siglo XV», en Bernal, Antonio M. (ed.), Dinero, moneda y crédito en la monarquía bispánica. Actas del Simposio Internacional "Dinero, moneda y crédito. De la Monarquía Hispánica a la Integración Monetaria Europea», Madrid, 4-7 de mayo de 1999. Madrid; 2000, pp. 121-134.

101 Puesto que las escrituras, entre ellas los asientos bancarios, se hacían en moneda de cuenta, un aumento del foro de la moneda significaba una disminución del metal a recibir en el momento de retirar el depósito o de cobrar las rentas.

102 CRUSAFONT: Història... p. 97.
} 
habrían condescendido más facilmente al aumento del croat y el florín en moneda de cuenta si, como se había hecho y se haría otras veces, se hubiesen revalorizado los depósitos bancarios, pero sólo obtuvieron una compensación parcial, que significó una pèrdida del $6 \%$ del valor de la moneda escrituraria $a^{103}$.

La política económica estaba a la vez bajo la dirección del municipio barcelonés y de la monarquía. En la ciudad, la discusión sobre cuáles debían ser la directrices de política económica motivó los enfrentamientos entre la biga y la busca, de los que ya hemos tratado. Alfonso el Magnánimo (1418-1458) intervino en estos enfrentamientos dando un verdadero golpe de estado contra las inexpugnables posiciones legales que los patricios habían construido para asegurarse el mantenimiento del poder municipal, pero, sobre todo desarrolló una política económica propia (de hecho una política propia que incluía directrices de política económica). La primera medida proteccionista, la prohibición de importación de paños extranjeros de lana, seda y oro, se tomó en 1422 y fue seguida en 1431 por un primer intento dirigista que no cuajó: la organización de una línea de navegación con Alejandría. Todo ello significaba abandonar la anterior libertad de comercio a cambio de una apuesta nueva, a la vez por el aumento de la producción artesana, la potenciación de la marina (con la prohibición de utilizar naves extranjeras) ${ }^{104}$, el proteccionismo comercial y la restricción de la libertad de actuación de los mercaderes extranjeros (hasta la repetida expulsión de los florentinos), todo lo cual se completaría tras la conquista de Nápoles con el intento de integrar los mercados de los dominios ibéricos e italianos, privilegiando el intercambio de tejidos de los territorios hispánicos de la corona con los trigos sicilianos, napolitanos o sardos. El proteccionismo comercial se completaba (pero era una actuación más tradicional) con la la protección y fomento del comercio de Levante, a través de diversos tratados, la mayoría de ellos de poca eficacia, subproductos como eran de los vastos y utópicos planes orientales del monarca. Con la decidida actuación de Alfonso el Magnánimo en la política económica está asomando ya el mercantilismo.

Sin negar diversos aspectos favorables, discrepo de del Treppo en la consideración como positiva del conjunto de la actuación del Magnánimo. Sin duda la situación después de la conquista de Nápoles y los privilegios que obtuvieron allí los mercaderes catalanes fueron una ayuda importante para la economía del Principado. El problema es el precio pagado por adelantado de la operación: la retención de naves y hombre en el Mediterráneo occidental, las pérdidas de naves, el dinero gastado, extraído del resto de la Corona, y lo que es peor, obtenido en ocasiones dictando medidas a cambio de dinero y dejándolas en suspenso si se le pagaba para hacerlo, lo que no hizo más que envenenar tanto el conflicto remença como el conflicto urbano.

\footnotetext{
103 FeliU: «Moneda...», p. 129.

104 En este deseo de potenciar la marina no cabe olvidar el papel de los planes militares del rey.
} 
Por todo ello, creo que la «aventura napolitana» comprometió el crecimiento y la recuperación económicos de Cataluña en unos años críticos; la sangría monetaria y las dificultades comerciales que provocó, difícilmente pudieron verse compensadas con los privilegios posteriores en el mercado napolitano ${ }^{105}$, beneficios que fueron a parar básicamente a una serie de hombres de negocios que se movían en el entorno real o al mismo rey, que actuaba igualmente como comerciante y por tanto en perjuicio del resto de mercaderes. Como afirma $\mathrm{Bresc}^{106}$, el imperialismo alfonsino iba acompañado de la tentativa a monopolizar los buenos negocios. Todo lo cual explica porqué la empresa de Nápoles fue altamente impopular entre los súbditos, incluso después de la conquista del reino ${ }^{107}$.

\section{CONCLUSIONES}

Casi más como programa de investigación que como conclusiones sólidas, mi visión de la crisis catalana de la Baja Edad Media puede resumirse de la forma siguiente:

1) la decadencia de la población y la producción limitan la capacidad de producción, de exportación y de mercado interior y provocan un aumento de los impuestos per capita, que sin embargo no parece superior en conjunto a la rebaja de las rentas feudales, de forma que la repercusión de este conjunto es muy diferencial: los campesinos que pudieron obtener rebajas en sus rentas o ampliar sus explotaciones salieron altamente beneficiados, pero sobre otros pesaría más el aumento de la presión impositiva. En todo caso, la crisis demográfica y agraria ha de entenderse más en el sentido de momento de cambio que como larga etapa de dificultades y su efecto sobre el conjunto de la economía fue limitado y muy retardado en el tiempo respecto a su supuesto motor, la Peste Negra.

2) En 1381-1383 se produce la crisis financiera, que es general en toda Europa, pero que en Cataluña tiene una mayor repercusión como consecuencia de la insolvencia de la monarquía ${ }^{108}$, que facilitó el asenta-

105 Todo ello dejando de lado que la descarada política de venta al mejor postor de las disposiciones reales tuvo mucho que ver con el desencadenamiento de la guerra civil.

106 BRESC: Un monde..., p. 303.

107 Bien es verdad que había también en ello diversas razones políticas, desde la ausencia del rey, que se consideraba perjudicial para el buen regimiento de la Corona, hasta el poder independiente que el rey obtenía con el dominio de Nápoles.

108 En la quiebra de la banca de des Caus y d'Olivella se mezclan diversas causas: la escasez de capitales que obligan a los banqueros a conceder altísimos intereses a los prestamistas; las necesidades perentorias de la Corona, que aceptaba cualquier condición; el atraso en los pagos, que hace crecer imparablemente la suma de capitales e intereses; la insuficiencia de los ingresos atribuidos a los banqueros para pagar los intereses vencidos; las turbias maniobras de una serie de cortesanos 
miento de la banca florentina ${ }^{109}$. A partir de 1415 , aparece con claridad la crisis del gran comercio; a pesar de que mostró todavía años de esplendor hasta cerca de 1440 (el momento de máximo esplendor puede situarse en el saqueo de Marsella en 1423) ${ }^{110}$, se trata de un crecimiento desacelerado y con beneficios decrecientes, a causa de la mayor competencia en todos los ámbitos (el sur de Francia, la meseta norte, Sevilla e incluso Flandes, en occidente), la piratería y la pérdida de mercados, pero en especial como consecuencia de la menor participación en el transporte y de la reducción del principal eje comercial en sus dos extremos; la retirada hasta Rodas (o Chipre) de las anteriores rutas a Alejandría o Damasco en oriente, hasta Barcelona o Zaragoza en el Mediterráneo occidental.

3) Los intentos de adaptación a la nueva situación durante la primera mitad del siglo XV (proteccionismo, dirigismo, imperialismo) permitieron frenar pero no detener la decadencia: estos años pueden considerarse claramente como el climaterio de la economía catalana, que entra en franca decadencia a partir de 1445 .

4) La guerra civil (1462-1472) llevaría la crisis al paroxismo, de manera que el final de la guerra (un compromiso por agotamiento) no supuso la recuperación económica, sino solamente una disminución de las dificultades.

5) Sólo muy a finales de siglo, con la serie de medidas y privilegios comerciales resultado de las cortes de 1480-1481 (que no tuvieron efecto hasta más tarde como consecuencia de la revuelta remença y de la introducción de la inquisición) y sobre todo con la liquidación del conflicto remença (1486) y la reforma monetaria de 1493 , se inició un camino de recuperación, que podemos simbolizar en la partida de una galera hacia Alejandría en 1495. Recuperación sin embargo insuficiente, que introduciría Cataluña en la Edad Moderna a muchas leguas del perdido esplendor medieval: aunque la decadencia fuese coyuntural, el atraso fue definitivo.

En definitiva, a mi entender no hay una crisi general catalana de la Baja Edad Media a través de una serie de mecanismos de decadencia encadenados a lo largo de casi dos siglos, sino una serie de momentos de crisis y otros tantos de crecimiento, a través de una amplia serie de factores internos y externos que

arribistas, que hicieron creer al rey que disponían de soluciones para resolver sus deudas sin necesidad de vender patrimonio y finalmente la decisión de Pedro el Ceremonioso de no hacer frente a unas deudas que limitaban en exceso su capacidad de actuación; FELIU, Gaspar: «El maestro racional...», p. 940-941.

109 VICENS I VIVES, J. «La economía... p. 85 (cito por la edición de 1969).

110 BAUTIER, Henri: «La place des États de la Couronne d'Aragon dans l'économie internationale du début du xv ${ }^{e}$ siècle», en VI Congreso de Historia de la Corona de Aragón. Madrid: 1959. 
actuan con gran autonomía ${ }^{111}$. El atraso con que Cataluña entra en la edad moderna se debe a la conjunción del agotamiento causado por la guerra civil, surgida de la coincidencia temporal de diversas crisis de tipo político y económico $^{112}$, el paso de la centralidad económica del Mediterráneo al Atlántico, el crecimiento de potencias vecinas (Castilla, Francia) que hasta este momento se habían desarrollado por debajo de sus posibilidades y la pérdida de la influencia sobre los resortes del estado. Los factores que habían influido en su grandeza medieval se aunaron para convertirla en un fondo de saco en el fondo de saco del Mediterráneo.

111 Mi opinión está pues más cercana a la consideración de la crisis bajomedieval como una sucesión de cuellos de botella (Epstein) que como una crisis sistémima (Bois); EPSTEIN, S. R.: Freedom and Growth. The Rise of States and Markets in Europe, 1300-1750. Londres, 2000, cap. III: «The late medieval crisis as an «integration crisis», esp. p. 39); BoIs, La gran depresión...

112 Bàsicamente: la crisis del comercio con Oriente, la insuficiencia del comercio con el Atlántico, la incapacidad para poner en pie una industria textil de calidad competitiva, las luchas sociales en la ciudad y el campo, la oposición entre las clases dominantes y la monarquía por el reparto del poder, o sea el enfrentamiento entre la legalidad constitucional y el autoritarismo monárquico, oposición expresada frente a la agotadora política imperial del Magnánimo y frente al contrafuero del comportamiento de Juan II respecto al príncipe de Viana. El «pactismo» posterior de Fernando el Católico significaba simplemente la neutralización de los conflictos, representada por la imposición del régimen de insaculación en todas las instituciones, aunque esta debilitación de cualquier institución capaz de oponerse al autoritarismo monárquico fue un fenómeno general europeo.

Hispania, LXIV/2, núm. 217 (2004) 435-466 